\title{
Allergen Immunotherapy in Pediatric Respiratory Allergy
}

Ali Doroudchi, $M D^{1}$

Kamran Imam, $M D^{2}$

Maria Ines Garcia Lloret, $M D^{1, *}$

\author{
Address \\ *,1Department of Pediatrics, David Geffen School of Medicine, University of \\ California, Los Angeles, Los Angeles, CA, USA \\ Email: migarcia@mednet.ucla.edu \\ ${ }^{2}$ Department of Internal Medicine, Adventist Health White Memorial Medical \\ Center, Los Angeles, CA, USA
}

Published online: 28 May 2021

(C) The Author(s) 2021

This article is part of the Topical Collection on Pediatric Dermatology and Allergy

Keywords AIT · SCIT · SLIT • Allergoids · Recombinant AIT · Immunogenicity

\begin{abstract}
Purpose of Review Atopic diseases such as asthma and allergic rhinitis are highly prevalent in children. Common triggers include tree and grass pollens, house dust mites, molds, and animal dander. These diseases are most often treated symptomatically; however, many patients show partial or poor response and require longterm medication use. Allergen immunotherapy (AIT) stands as the only treatment modality that can alter the underlying disease process and potentially offer a cure. In this review article, we discuss the merits of AIT with particular emphasis on its efficacy and safety in pediatric patients. We also discuss the challenges for AIT implementation and present an overview of current research that aims at improving its applicability for the treatment of allergic diseases.

Recent Findings Subcutaneous immunotherapy (SCIT) and sublingual immunotherapy (SLIT) are both safe and efficacious treatment options in children with allergic rhinitis and allergic asthma. Additionally, AIT has efficacy in preventing the development of asthma in children. Although there are clear advantages with AIT, there are challenges to overcome to optimize treatment. Solutions include improved diagnostics with pre-treatment biomarkers and molecular multiplex assays, biomarkers for prediction of response (e.g., basophil activation markers), improved allergen immunogenicity with the use of recombinant AIT, adjuvants, and allergoids, and lastly improved safety with the concurrent use of omalizumab.

Summary AIT has shown safety and efficacy in major clinical trials for the treatment of allergic rhinitis and allergic asthma in children. AIT provides a curative treatment
\end{abstract}


option for atopic disorders and should be considered in children with allergic rhinitis and allergic asthma. There are many continued advances being made in the field of allergy to further improve the safety and efficacy profile and shorten the duration of AIT treatment.

\section{Introduction}

Allergic diseases such as atopic asthma and allergic rhinitis are among the most common chronic childhood illnesses, and their prevalence has grown worldwide over the last fifty years [1]. These diagnoses have a significant impact on children's quality of life and place considerable financial burden on families and healthcare systems.

Treatment for these disorders is classically addressed symptomatically, with the most common methods being allergen avoidance, oral or nasal antihistamines and/or intranasal steroids for allergic rhinitis, and bronchodilators and/or inhaled steroids for asthma. Surveys in the U.S. and the U.K. querying the efficacy of first-line treatment for allergic rhinitis have shown that up to $29 \%$ of children and $60 \%$ of adults have reported poor or partial response to standard treatments [2, 3]. As these medications are not curative, treatments are by necessity long term. This poses an additional problem in pediatrics due to factors such as poor adherence by young patients as well as parental concerns regarding the possible side effects of long-term medication use for a young, growing child.

In use since the early $20^{\text {th }}$ century, allergen immunotherapy (AIT) stands as the only treatment known to have a modulating effect on the immunological cascade that drives atopic disease. It consists of exposing patients to increasing amounts of an allergen extract, with the goal of achieving tolerance, thereby reducing symptoms upon natural exposure to a sensitizing allergen. AIT is accepted as an effective therapy for allergic rhinitis (with or without conjunctivitis), well-controlled allergic asthma, hymenoptera hypersensitivity, and food allergy. It is currently recommended for patients 5 years and older and can also be considered for younger children [4]. Traditionally, AIT had been delivered subcutaneously (SCIT), however, sublingual immunotherapy (SLIT) has emerged as a safer and comparably efficacious modality, with the WHO accepting SLIT as a viable alternative in 1998 [5].

In conventional SCIT, administration schedules consist of a build-up phase in which injections are administered once to twice weekly for 3-6 months, followed by a maintenance phase in which injections are administered at 4-8 week intervals for a total treatment duration of 3-5 years. Injections should be administered in the clinic with a 30-minute observation period for any adverse reactions. On the contrary, SLIT can be taken in a patient's home and involves anywhere from three-times weekly to daily sublingual administrations (tablet or liquid extracts) for a similar duration of 3-5 years. There are currently 4 FDA-approved SLIT tablet products (Timothy grass [Grastek], 5-grass [Oralair], ragweed [Ragwitek], and HDM [Odactra]), of which only Grastek is approved in children. Meanwhile, droplets are currently only used off-label in the United States. Intralymphatic and epicutaneous immunotherapy are the most novel modalities showing comparable efficacy to SCIT in grass pollen trials [6]. The former requires fewer injections relative to SCIT, while the latter requires no injections at all, as it is administered through an epidermal patch.

In spite of its long-standing usage, efficacy, and favorable safety profile, there remain gaps in knowledge and concerns regarding the practice of AIT, particularly within the field of pediatrics. Although these challenges exist, there are significant advances being made, ranging from improved diagnostic techniques, biomarkers for predicting efficacy, optimization of allergen extracts, and allergen modification together with a continued expansion in our 
understanding behind the mechanisms of AIT. In this article, we will discuss the efficacy favoring the use of AIT in pediatrics, while also discussing the challenges facing this treatment modality.

\section{Mechanisms of Allergy and AIT}

The allergic response is initiated by allergen binding to its cognate IgE present on mast cells and basophils. Crosslinking of the high-affinity IgE receptor (FcER1) by these antigen/IgE complexes triggers mast cell and basophil degranulation with the release of inflammatory mediators [7•]. The production of IgE against innocuous antigens (e.g., foods and pollens) is attributed to dysregulated type 2 responses, consisting of Th2 cells, ILC2s, and cytotoxic T cells (TC2) characterized by a signature cytokine profile that includes IL-4, IL-5, and IL-13 [8], in addition to recently uncovered cytokines, IL-25, IL-31, and IL-33 [9]. Besides facilitating IgE production through B-cell class switching, these interleukins also promote mast cell and basophil activation, eosinophilia, and directly affect endothelium permeability, mucus production, and smooth muscle contractility [10].

AIT has been shown to decrease mast cell and basophil degranulation within a single administration, and this suppression is sustained throughout the course of therapy [8]. This mechanism is not clearly understood, but appears to be similar to that occurring during rapid desensitization to drug hypersensitivities [9]. An important recognized downstream effect of AIT (after months to years) is the reduction in the population of mast cells, basophils, as well as eosinophils, and ILC2 cells in target organs [11-14].

AIT has also been shown to alter the Th2 profile toward a tolerant state via increased regulatory immune cells-Treg and Breg cells. Importantly, the induction of tolerant peripheral T cells appears to be driven by IL-10 and TGF- $\beta$ [9]. TGF- $\beta$ induces the conversion of naïve T cells into CD4+CD25+ T cells through the expression of FOXP3 [15]. Additionally, another regulatory cell subset-BR1 (regulatory B cells) - has been shown to increase in response to AIT [16].

When AIT is initiated, there is an initial transient increase in serum allergenspecific IgE, followed by a gradual decline over the treatment course. However, decreases in IgE alone do not always correlate with clinical improvement [8]. AIT also results in the increase of other immunoglobulins, particularly IgG4, as well as IgG1 and IgA2. This occurs in the setting of increased IFN- $\gamma$, IL-10, and TGF- $\beta$ [7•]. IgG4 is thought to confer a protective effect by directly competing with allergen-specific IgE for the binding to the same epitopes on allergens [17]. The mechanisms of AIT discussed in this section are illustrated in Fig. 1.

\section{Efficacy and Preventative Role of AIT in Pediatrics}

The Allergic Rhinitis and its Impact on Asthma (ARIA) guidelines as well as the European Academy of Allergy and Clinical Immunology (EAACI) guidelines 


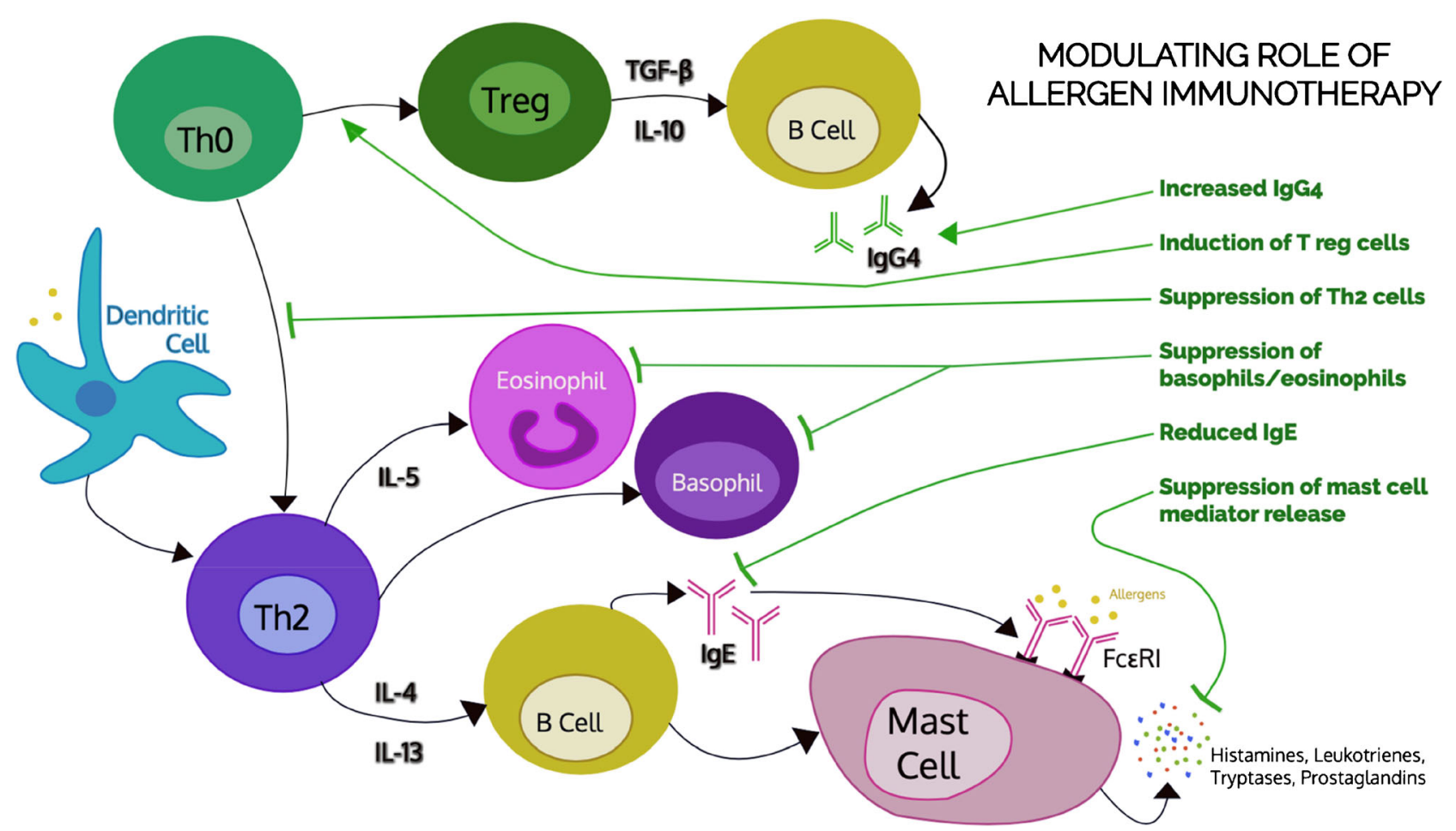

Fig. 1. Illustrative summary of the major mechanisms of modulation in allergen immunotherapy. In summary, AIT results in suppression of Th2 cells, with a downstream reduction of IgE, eosinophils, basophils, and mast cells. There is an increase in Treg cells-with downstream increase in IL-10 and TGF- $\beta$ expression, resulting in increased protective IgG4. Mechanisms not depicted include an increase in tolerogenic dendritic cells (DCs), B regulatory cells, and suppression of inflammatory DCs.

have determined that AIT is an effective modality for children with moderate to

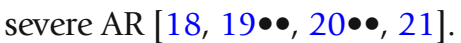

The conclusions on efficacy are based on a large number of international trials demonstrating AIT's effectiveness in pediatric AR patients. The majority of studies are based on symptomatology. Symptoms are traditionally measured by a scoring system involving both ocular and nasal symptoms known as Total Nasal Scoring System (TNSS). It involves four conventional symptoms-sneezing, congestion, itching, and rhinorrhea-graded from 0 to 3 with $0=$ no symptoms, $1=$ easily tolerated, $2=$ bothersome, but tolerable, and $3=$ interferes with daily activities. The scoring symptoms were added up and stratified from $0=$ best to $12=$ worst, and symptoms were reassessed after the treatment period (Table 1).

In a major meta-analysis of 160 studies prepared during the development of EAACI's clinical recommendations on AIT for allergic rhinoconjunctivitis, standardized mean differences (SMD) were significant for symptom improvement $(-0.53)$, medication usage $(-0.37)$, and combined symptom and medication scores (-0.49). Importantly, the authors stratified data for adults versus children

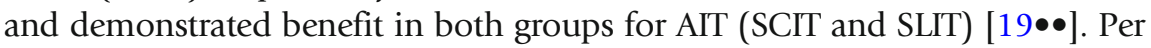
this data, the EAACI stated that for children with moderate to severe AR, preseasonal, co-seasonal, and/or continuous AIT is recommended for clinical 
Table 1. Approaches in use and in development for the improvement of AIT

\begin{tabular}{|c|c|}
\hline Challenges & Solutions \\
\hline Diagnostic accuracy & $\begin{array}{l}\text { Biomarkers (e.g., sIgE/tIgE) } \\
\text { Singleplex and multiplex assays }\end{array}$ \\
\hline Response prediction & $\begin{array}{l}\text { Biomarkers for efficacy: } \\
\text { (1) sIgE >10 kU/L (HDM) } \\
\text { (2) Basophils activation (CD63, CD203c, diamine oxidase (DAO), } \\
\text { basophil histamine release) } \\
\text { (3) IgG subclass quantification (sIgE/IgG4) } \\
\text { (4) Serum inhibitory activity (IgE-FAB) } \\
\text { (5) Quantification of Tregs and tolerogenic dendritic cells } \\
\text { (6)Micro-RNA expression profiles }\end{array}$ \\
\hline Immunogenicity & $\begin{array}{l}\text { Adjuvants } \\
\text { Recombinant AIT } \\
\text { Allergoids }\end{array}$ \\
\hline Safety of AIT & $\begin{array}{l}\text { SLIT } \\
\text { Concurrent omalizumab } \\
\text { Recombinant AIT } \\
\text { Adjuvants } \\
\text { Allergoids }\end{array}$ \\
\hline Duration of AIT & $\begin{array}{l}\text { Cluster build-up phases } \\
\text { Recombinant AIT } \\
\text { Adjuvants } \\
\text { Allergoids } \\
\text { Alternate routes of delivery (e.g., intralymphatic) }\end{array}$ \\
\hline
\end{tabular}

benefit in both seasonal and perennial AR, despite the gaps in evidence in pediatric data relative to adults $[20 \bullet \bullet]$.

Overall, the current data is insufficient to determine whether SCIT or SLIT is more efficacious. A meta-analysis of 37 studies showed that SLIT and SCIT had similar significant reductions in symptoms and medication usage in patients with grass pollen allergies, relative to placebo [22]. Similarly, randomized control trials (RCTs) of birch tree pollen have shown similar efficacy between the two forms of AIT relative to placebo [23]. The exception may rest with house dust mite (HDM), in which there have been conflicting results; some RCTs demonstrate an advantage towards SCIT, while others have shown similar

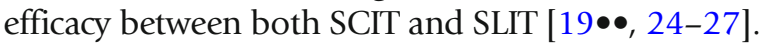

For allergic asthma, both SCIT and SLIT have demonstrated efficacy in symptom control and medication reduction in adults and children [28, 29]. A meta-analysis that included 441 pediatric patients (3-18 years old) with allergic asthma treated with SLIT showed significant reductions in symptoms and medication usage compared to placebo [30]. Furthermore, a prospective study of 60 pediatrics asthma patients treated with HDM SLIT showed a reduction in asthma symptoms and medication usage $4-5$ years after cessation of AIT [31]. In a retrospective study of 48 pediatric patients treated with HDM or both HDM/ grass pollen SCIT, follow-up between 7 and 11 years after cessation of AIT showed a 3-fold reduction in asthma symptoms [32]. Comparisons between 
SLIT and SCIT are summarized in Table 2.

In addition to its efficacy in the treatment of allergic disease, AIT has been shown to play a role in the prevention of asthma development in children. In 2006, the prevention of allergy (PAT) study investigated SCIT therapy in 205 children with allergic rhinoconjunctivitis (without asthma) to grass and/or birch pollen. This landmark study showed that patients had a reduced risk of developing asthma at 3-, 5-, and 10-year observations points following treatment [33]. A risk reduction for asthma development was found in two other randomized SLIT trials in 2004 and 2008 [34, 35]. The most robust SLIT trial to date, the Grazax Asthma Prevention (GAP) trial, was a randomized, doubleblind, placebo-controlled study of 812 children published in 2018 [36••]. The use of grass SLIT for 3 years demonstrated a reduced risk of asthma symptoms and asthma medication usage at the end of 3 years of treatment and after a 2year follow-up. Notably, the number needed to treat (NNT) increased with age, suggesting that earlier treatment may have the highest potential for benefit in patients. Indeed, there is increasing evidence for the efficacy of AIT in patients under 5 years old [37]. In further support of earlier treatment, children have a higher risk of respiratory disease despite a lower number of sensitizations compared to adults and are more frequently mono-sensitized at younger ages $[38 \bullet$.

\section{Challenges Facing AIT and the Advances Being Made to Overcome Them}

Despite the established merits of allergen immunotherapy, there still remain challenges to further improve its efficacy, safety, and duration of treatment. The lengthy duration associated with AIT has a negative impact on adherence, with studies demonstrating attrition rates of $45 \%$ and $41 \%$ for SCIT and SLIT, respectively [39]. Market data from European manufacturers has additionally shown similar attrition rates $(\sim 50 \%)$ within 2 to 3 years of initiating treatment $[40,41]$.

Table 2. Comparison profiles of SCIT versus SLIT

\begin{tabular}{lcc}
\hline & Subcutaneous & Sublingual \\
Efficacy & $\checkmark \checkmark \checkmark$ & $\checkmark \checkmark$ \\
Efficacy in seasonal rhinitis** & $\checkmark \checkmark$ & $\checkmark \checkmark \checkmark$ \\
Efficacy in perennial rhinitis** & $\checkmark$ & $\checkmark \checkmark$ \\
Prevention of asthma & $\checkmark \checkmark$ & $\checkmark \checkmark$ \\
Adherence monitoring & $\checkmark \checkmark \checkmark$ & $\checkmark$ \\
Ease of use & $\checkmark$ & $\checkmark \checkmark \checkmark$ \\
Safety/side effect profile & $\checkmark \checkmark$ & \\
*Level of evidence regarding efficacy is comparable across subcutaneous and sublingual. **2017 ECAAI Guidelines on Allergen Immunotherapy \\
Recommendations [12]: SCIT in seasonal pediatric allergic rhinitis_Grade B; SCIT in perennial pediatric allergic rhinitis-Grade B-C; SLIT in \\
seasonal pediatric allergic rhinitis-Grade A; SLIT in perennial pediatric allergic rhinitis-Grade A-C
\end{tabular}


Improved patient selection and diagnosis, identification of biomarkers to predict response, optimization and standardization of extract content, and creating novel methods of design and delivery of AIT are all means by which AIT can gain more efficacy and safety, while shortening necessary treatment durations. Altogether, this can improve patient outcomes, making AIT an even more attractive therapy for individuals with respiratory allergies.

\section{Biomarkers for Diagnosis and Patient Selection}

Effective treatment of allergy begins with the identification of a specific allergen (or allergens) responsible for driving the disease. Such identification allows for allergen-specific interventions. There is a vast heterogeneity of sensitization profiles among allergic patients, which creates the challenge of identifying which allergen(s) are clinically relevant for any given patient. Tripodi et al. demonstrated this heterogeneity in patient sensitization profiles to Pleum pretense. Using serum IgE assays, the authors tested for reactivity against 9 different P. pretense molecules ( $\mathrm{rPh} 1 \mathrm{p} 1, \mathrm{rPhl} \mathrm{p} 2$, etc.). They found that only 7 of 176 patients (4\%) had a sensitization profile that actually matched the composition of a standardized immunotherapy extract, while the remaining 169 patients were classified into mismatch categories [42]. Additionally, up to $80 \%$ of patients are polysensitized [43], by that meaning that they produce high IgE against multiple allergens. Determining which allergens to include in the extracts is challenging but critical for AIT efficacy.

The established methods for identifying a patient's sensitization profile consist of a detailed allergic history, skin prick testing (SPT), and specific-IgE (sIgE) via a serum sample. While these are helpful in the identification of a suspected allergen, further improvement is needed in determining whether sensitization results in clinical symptomatology, particularly in patients with polysensitization, as well as for patients with non-specific and clinically-irrelevant cross-reactivity. Approaches under investigation include measuring sIgE/tIgE (specific IgE/total IgE (i.e., serum IgE)) prior to treatment [44•], as well as improved assays for the detection of allergen sensitization profiles. Molecular multiplex assays can provide both detailed sensitization profiles, while distinguishing genuine sensitizations from the abovementioned cross-reactions $[45,46]$. Interestingly, an Italian study showed that when provided with molecular serological results of their patient, allergists were more likely to change their management in favor of AIT for $42-48 \%$ of patients [47]. This highlights the importance of an accurate allergic diagnosis prior to initiating AIT.

\section{Biomarkers for Predicting Response}

In the era of precision medicine, it is indispensable to look for reliable biomarkers that predict the efficacy of AIT in a particular patient. A study of 31 HDM-allergic children found that a sIgE cut-off level of $>10 \mathrm{kU} / \mathrm{l}$ significantly correlated with AIT efficacy using a symptom and drug use scale $(r=0.615$; $p<0.001)$ [48]. Other candidate response biomarkers under investigation for predicting efficacy includes basophil activation markers (CD63, CD203c, diamine oxidase (DAO), and basophil histamine release), IgG subclass quantification with sIgE/IgG4 ratio, serum inhibitory activity for IgE (IgE-FAB), quantification of Tregs, and tolerogenic dendritic cells, as well as micro-RNA expression profiles $[44 \bullet, 49-51]$. 


\section{Extract Content, Potency, and Standardization}

The lack of standardization of extracts used in trials and in clinical practice remains a confounding element in objectively assessing AIT's efficacy. There is a wide variety of allergen extracts on the market, ranging from unmodified extracts (including purified, adsorbed, recombinant, and synthetic peptides) as well as modified extracts [38•]. Additionally, there is variability in the units of measurement used between manufacturers, as well as the content and potency of allergens between different products $[52,53]$. Lastly, there is inconsistency in the quality of extracts, as several studies analyzing the composition of natural extracts have demonstrated the presence of non-allergenic components as well as contaminants [54].

Optimal extract preparation is aimed at preserving the natural variability of any given allergen, while maximizing the amounts of major allergen-the allergen to which the majority of patients are sensitized to. After the process of extraction, comes the challenge of standardization among different manufacturers. As mentioned previously, there are both standardized and nonstandardized extracts available on the market. Needless to say, standardized extracts are the preferred product for consistency, reliability, and patient safety, as they provide documented composition and potency [55]. In the U.S., only short ragweed pollen, cat hair/pelt, house dust mite, and grass pollen extracts are available in standardized form.

An added degree of variability in extract-based allergen products is the different units of measure for product content as well as product potency. Most allergen extracts on the market are not standardized and have no standard of potency. These often only have units of measure that reflect protein content, such as the protein nitrogen unit (PNU) or weight by volume ratio (w/v) [55]. Generally, these do not provide clinicians with useful information as to the potency or immunogenicity of the product. A much more valuable unit is the bioequivalent allergy unit (BAU), endorsed by the FDA in the United States and most often used in standardized extracts [55]. BAU provides a standardized measure of potency, based on intradermal skin tests elicited by dilution series of a reference extract [8].

\section{Improving Allergen Content and Immunogenicity}

An approach to resolving the problem presented with extract-based AIT is the use of recombinant allergens. Recombinant allergens could potentially improve the quality of introduced allergen, thereby maximizing the efficacy of treatment, while ensuring a standardized product for patients. Recombinant strategies include recombinant wildtype allergens, synthetic peptides, nucleic acids, hypoallergenic allergens, and peptides capable of inducing protective IgG responses. Although recombinant allergens are considered a safer and more specific form of AIT relative to allergen extract-based AIT, the progress of this modality has been slow since its inception over 30 years ago [56].

Another modality under continued investigation is allergoids -chemically modified allergens. The modifications result in decreased IgE binding activity while still inducing $\mathrm{T}$ cell tolerance, effectively allowing for higher doses of allergen administration while lowering safety concerns, 
notably anaphylaxis [57]. Several different classes of allergoids have proven efficacy in trials for ragweed, grass, tree pollen, and house dust mite allergy [58-62].

Other platforms in development also aim to improve allergen immunogenicity. The adjuvant aluminum salt (alum) is the best example of an established and already licensed approach, currently used with SCIT in Europe. Alum, a depot, has the function of activating both innate and adaptive immune responses [63]. A more novel depot agent includes microcrystalline tyrosine (MCT), shown to have similar Th1 promoting properties $[7 \bullet]$. More novel adjuvant approaches include toll-like receptor (TLR) ligands, particularly monophosphoryl lipid A (MPL), a TLR-4 ligand. MPL leads to the activation of innate and adaptive pathways [64]. Grass pollen trials thus far have shown efficacy with as few as four pre-seasonal injections [65]. Other adjuvants with promising phase 2 efficacy include lipophilic liposomes [66] and virus-like particles [67], both of which increase antigen presentation efficiency directly into the lymphatic system, while minimizing the risk of mast cell degranulation in tissues [ $7 \bullet]$. Other coupling methods include CpG oligonucleotide-conjugated allergens [68] and carbohydrate-based particles [69].

Strategies discussed above provide improved the introduction of tolerogenic components of an allergen to a patient, and thereby minimize adverse effects, while improving immunogenicity, and, thus, maximizing efficacy and safety. A summary of these approaches discussed are listed under Table 1.

Safety during the administration of immunotherapy is a particular concern of providers, especially when dealing with pediatric patients. Although the safety data has been favorable for AIT, systemic reactions do occur and pose a source of hesitation for some families. Although AIT is considered efficacious in the treatment of allergic asthma, severe or uncontrolled asthma is an absolute contraindication due to the increased risk of systemic reaction [70].

In a SCIT study including 2441 children, 1.2\% experienced systemic reactions, including anaphylaxis [71]. Notably, there have been reported fatalities caused by SCIT; by 1986, there were 26 deaths associated with SCIT [7•]. In recent decades, SLIT has become a well-validated alternative to SCIT, with fewer systemic adverse events. In a systematic review of SLIT (5131 patients, 1814 children), 0.056\% experienced systemic reactions [72]. SLIT does carry the risk of local reactions (i.e., oral pruritus and tissue edema); however, these have been found to be self-resolving within the first few administrations of an extract [73].

Comparisons of treatment safety between standard, cluster, and rush buildup phases (i.e., more rapid allergen introduction schedules) have shown rush AIT to be the least safe method, with a 30-fold increase in per-shot incidences of systemic reactions in rush compared to standard build-up schedules [74]. Cluster build-up schedules, however, may represent a "middle ground" between standard and rush schedules. A meta-analysis of 6 studies showed no difference in local or systemic adverse reactions between cluster and standard build up [75]. 


\section{Conclusion}

The use of biologics, specifically anti-IgE (omalizumab), has been shown to have added a safety profile by decreasing the risk of anaphylaxis when administered with AIT [17].

In summary, AIT is a safe and effective treatment for children with allergic rhinitis and allergic asthma, particularly given its preventative role in future asthma development. SLIT can be a particularly advantageous modality for children as it has similar efficacy and a superior safety profile relative to SCIT, while avoiding the need for frequent injections for children. However, the drawbacks for SLIT include a lack of commercially-available tablets for children and the fact that droplets are non-FDA approved and are currently used off-label.

Although limitations exist, AIT stands as the only treatment modality that can alter the underlying disease process and provide a definitive cure for allergic disease. In addition to its established safety and efficacy, many exciting and promising advances are being contributed to the field to further solidify AIT's safety and efficacy profile, while improving patient adherence with shorter treatment regimens.

\section{Author Contribution}

$\mathrm{AD}$ and MGL were responsible for the original design and focus of the article. $\mathrm{AD}$ and KI performed the literature search and wrote sections of the article. MGL edited the final version and performed the final review.

\section{Declarations}

\section{Conflict of Interest}

Ali Doroudchi, Kamran Imam, and Maria Ines Garcia Lloret declare that they have no conflicts of interest.

Human and Animal Rights and Informed Consent

This article does not contain any studies with human or animal subjects performed by any of the authors.

Open Access This article is licensed under a Creative Commons Attribution 4.0 International License, which permits use, sharing, adaptation, distribution and reproduction in any medium or format, as long as you give appropriate credit to the original author(s) and the source, provide a link to the Creative Commons licence, and indicate if changes were made. The images or other third party material in this article are included in the article's Creative Commons licence, unless indicated otherwise in a credit line to the material. If material is not included in the article's Creative Commons licence and your intended use is not permitted by statutory regulation or exceeds the permitted use, you will need to obtain permission directly from the copyright holder. To view a copy of this licence, visit http://creativecommons.org/licenses/by/4.0/. 


\section{References and Recommended Reading}

Papers of particular interest, published recently, have been highlighted as:

- Of importance

- Of major importance

1. Bloom B, Jones LI, Freeman G. Summary health statistics for U.S. children: National Health Interview Survey, 2012. Vital Health Stat. 2013;10(258):1-81.

2. Meltzer EO, Blaiss MS, Derebery MJ, Mahr TA, Gordon BR, Sheth KK, et al. Burden of allergic rhinitis: results from the Pediatric Allergies in America survey. J Allergy Clin Immunol. 2009;124(suppl):S43-70.

3. White P, Smith H, Baker N, Davis W, Frew A. Symptom control in patients with hay fever in UK general practice: how well are we doing and is there a need for allergen immunotherapy? Clin Exp Allergy. 1998;28:266-70.

4. Cox L, Esch RE, Corbett M, Hankin C, Nelson M, Plunkett G. Allergen immunotherapy practice in the United States: guidelines, measures, and outcomes. Ann Allergy Asthma Immunol. 2011;107(4):289-99.

5. CSM Update: Desensitizing vaccines. Br Med J (Clin Res Ed). 1986;293(6552):948.

6. Akdis CA, Akdis M. Advances in allergen immunotherapy: aiming for complete tolerance to allergens. Sci Transl Med. 2015;7(280):280ps6.

7. $\quad$ Gunawardana NC, Durham SR. New approaches to allergen immunotherapy. Ann Allergy Asthma Immunol. 2018;121(3):293-305.

Excellent review article highlighting methods of further improving AIT's efficacy.

8. Akdis M, Akdis CA. Mechanisms of allergen-specific immunotherapy: multiple suppressor factors at work in immune tolerance to allergens. J Allergy Clin Immunol. 2014;133(3):621-31. https://doi.org/10. 1016/j.jaci.2013.12.1088.

9. Akdis CA, Akdis M. Mechanisms of allergen-specific immunotherapy and immune tolerance to allergens. World Allergy Organ J. 2015;8(1):17.

10. Romagnani S. Immunologic influences on allergy and the TH1/TH2 balance. J Allergy Clin Immunol. 2004; 113:395-400.

11. Nouri-Aria KT, Pilette C, Jacobson MR, Watanabe H, Durham SR. IL-9 and c-kit1 mast cells in allergic rhinitis during seasonal allergen exposure: effect of immunotherapy. J Allergy Clin Immunol. 2005;116:739.

12. Passalacqua G, Albano M, Fregonese L, Riccio A, Pronzato C, Mela GS, et al. Randomised controlled trial of local allergoid immunotherapy on allergic inflammation in mite-induced rhinoconjunctivitis. Lancet. 1998;351:629-32.

13. Wilson DR, Nouri-Aria KT, Walker SM, Pajno GB, O'Brien F, Jacobson MR, et al. Grass pollen immunotherapy: symptomatic improvement correlates with reductions in eosinophils and IL-5 mRNA expression in the nasal mucosa during the pollen season. J Allergy Clin Immunol. 2001;107:971-6.

14. Lao-Araya M, Steveling E, Scadding GW, Durham SR, Shamji MH. Seasonal increases in peripheral innate lymphoid type 2 cells are inhibited by subcutaneous grass pollen immunotherapy. J Allergy Clin Immunol. 2014;134:1193-5.e4.

15. Chen W, Jin W, Hardegen N, Lei KJ, Li L, Marinos N, et al. Conversion of peripheral CD4 + CD25- naive T cells to CD $4+\mathrm{CD} 25+$ regulatory $\mathrm{T}$ cells by TGF-beta induction of transcription factor Foxp3. J Exp Med. 2003;198:1875-86.

16. van de Veen $W$, Stanic B, Yaman G, Wawrzyniak M, Söllner S, Akdis DG, et al. IgG4 production is confined to human IL-10-producing regulatory B cells that suppress antigen-specific immune responses. J Allergy Clin Immunol. 2013;131(4):1204-12.

17. Klunker S, Saggar LR, Seyfert-Margolis V, Asare AL, Casale TB, Durham SR, et al. Combination treatment with omalizumab and rush immunotherapy for ragweed-induced allergic rhinitis: inhibition of IgEfacilitated allergen binding. J Allergy Clin Immunol. 2007;120(3):688-95.

18. Bachert C, Larché M, Bonini S, Canonica GW, Kündig $\mathrm{T}$, Larenas-Linnemann $\mathrm{D}$, et al. Allergen immunotherapy on the way to product-based evaluation-a WAO statement. World Allergy Organ J. 2015;8(1):29.

19.• Dhami S, Nurmatov U, Arasi S, Khan T, Asaria M, Zaman $\mathrm{H}$, et al. Allergen immunotherapy for allergic rhinoconjunctivitis: a systematic review and metaanalysis. Allergy. 2017;72:1597-631. https://doi.org/ $10.1111 /$ all.13201

This paper is an excellent meta-analysis on AIT for AR.

20.• Muraro A. et al. EAACI Guidelines on Allergen Immunotherapy: Allergic rhinoconjunctivitis. Allergy. 2018 Apr;73(4):765-798. https://doi.org/10.1111/all. 13317.

Review of the 2017 European Guidelines on AIT.

21. Brozek JL, Bousquet J, Baena-Cagnani CE, Bonini S, Canonica GW, Casale TB, et al. Allergic Rhinitis and its Impact on Asthma (ARIA) guidelines: 2010 revision. J Allergy Clin Immunol. 2010 Sep;126(3):466-76.

22. Nelson H, Cartier S, Allen-Ramey F, Lawton S, Calderon MA. Network meta-analysis shows commercialized subcutaneous and sublingual grass products have comparable efficacy. J Allergy Clin Immunol Pract. 2015;3(2):256-266.e3. 
23. Khinchi MS, Poulsen LK, Carat F, André C, Hansen AB, Malling HJ. Clinical efficacy of sublingual and subcutaneous birch pollen allergen-specific immunotherapy: a randomized, placebo-controlled, double-blind, double-dummy study. Allergy. 2004;59(1):45-53.

24. Keles S, Karakoc-Aydiner E, Ozen A, Izgi AG, Tevetoglu A, Akkoc T, et al. A novel approach in allergen-specific immunotherapy: combination of sublingual and subcutaneous routes. J Allergy Clin Immunol. 2011;128:808-15.

25. Eifan AO, Akkoc T, Yildiz A, Keles S, Ozdemir C, Bahceciler NN, et al. Clinical efficacy and immunological mechanism of sublingual and subcutaneous immunotherapy in asthmatic/rhinitis children sensitized to house dust mite: an open randomized controlled trial. Clin Exp Allergy. 2010;40:922-32.

26. Mungan D, Misirligil Z, Gurbuz L. Comparison of the efficacy of subcutaneous and sublingual immunotherapy in mite-sensitive patients with rhinitis and asthma-a placebo controlled study. Ann Allergy Asthma Immunol. 1999;82:485-90.

27. Tahamiler R, Saritzali G, Canakcioglu S, Ozcora E. Comparison of the long-term efficacy of subcutaneous and sublingual immunotherapies in perennial rhinitis. ORL J Otorhinolaryngol Relat Spec. 2008;70:144-50.

28. Abramson MJ, Puy RM, Weiner JM. Injection allergen immunotherapy for asthma. Cochrane Database Syst Rev. 2010;8:CD001186.

29. Ross RN, Nelson HS, Finegold I. Effectiveness of specific immunotherapy in the treatment of asthma: a meta-analysis of prospective, randomized, doubleblind, placebo-controlled studies. Clin Ther. 2000;22(3):329-41.

30. Penagos M, Passalacqua G, Compalati E, BaenaCagnani CE, Orozco S, Pedroza A, et al. Metaanalysis of the efficacy of sublingual immunotherapy in the treatment of allergic asthma in pediatric patients, 3 to 18 years of age. Chest. 2008;133(3):599-609.

31. Di Rienzo V, Marcucci F, Puccinelli P, Parmiani S, Frati F, Sensi L, et al. Long-lasting effect of sublingual immunotherapy in children with asthma due to house dust mite: a 10-year prospective study. Clin Exp Allergy. 2003;33(2):206-10.

32. Cools M, Van Bever HP, Weyler JJ, Stevens WJ. Longterm effects of specific immunotherapy, administered during childhood, in asthmatic patients allergic to either house-dust mite or to both house-dust mite and grass pollen. Allergy. 2000;55:69-73. https://doi.org/ 10.1034/j.1398-9995.2000.00191.x.

33. Niggemann B, Jacobsen L, Dreborg S, Ferdousi HA, Halken S, Høst A, et al. Five-year follow-up on the PAT study: specific immunotherapy and long-term prevention of asthma in children. Allergy. 2006;61(7):855-9.

34. Novembre E, Galli E, Landi F, Caffarelli C, Pifferi M, De Marco E, et al. Coseasonal sublingual immunotherapy reduces the development of asthma in children with allergic rhinoconjunctivitis. J Allergy Clin Immunol. 2004;114(4):851-7.

35. Marogna $M$, Tomassetti D, Bernasconi A, Colombo F, Massolo A, Businco AD, et al. Preventive effects of sublingual immunotherapy in childhood: an open randomized controlled study. Ann Allergy Asthma Immunol. 2008;101(2):206-11.

36.• Valovirta E, Petersen TH, Piotrowska T, Laursen MK, Andersen JS, Sørensen HF, et al. Results from the 5-year SQ grass sublingual immunotherapy tablet asthma prevention (GAP) trial in children with grass pollen allergy. J Allergy Clin Immunol. 2018;141(2):529538.e13.

Pivotal study demonstrating preventive role of AIT in asthma development.

37. Cox L, Nelson H, Lockey R, Calabria C, Chacko T, Finegold I, et al. Allergen immunotherapy: a practice parameter third update. J Allergy Clin Immunol. 2011;127(1 Suppl):S1-55.

38. - Passalacqua G, Bagnasco D, Canonica GW. 30 years of sublingual immunotherapy. Allergy. 2019. https:// doi.org/10.1111/all.14113

Thorough overview on the use of SLIT.

39. Hsu NM, Reisacher WR. A comparison of attrition rates in patients undergoing sublingual immunotherapy vs subcutaneous immunotherapy. Int Forum Allergy Rhinol. 2012;2(4):280-4. https://doi.org/10.1002/alr. 21037.

40. Senna G, Lombardi C, Canonica GW, Passalacqua G. How adherent to sublingual immunotherapy prescriptions are patients? The manufacturers' viewpoint. J Allergy Clin Immunol. 2010;126(3):668-9. https:// doi.org/10.1016/j.jaci.2010.06.045.

41. Sieber J, De Geest S, Shah-Hosseini K, Mösges R. Medication persistence with long-term, specific grass pollen immunotherapy measured by prescription renewal rates. Curr Med Res Opin. 2011;27(4):855-61. https:// doi.org/10.1185/03007995.2011.559538.

42. Tripodi S, Frediani T, Lucarelli S, Macrì F, Pingitore G, Di Rienzo Businco A, et al. Molecular profiles of IgE to Phleum pratense in children with grass pollen allergy: implications for specific immunotherapy. J Allergy Clin Immunol. 2012;129(3):834-839.e8.

43. Jutel M, Agache I, Bonini S, Burks AW, Calderon M, Canonica W, et al. International consensus on allergen immunotherapy II: mechanisms, standardization, and pharmacoeconomics. J Allergy Clin Immunol. 2016;137:358-68. https://doi.org/10.1016/j.jaci.2015. 12.1300 .

44. $\quad$ Tosca MA, Licari A, Olcese R, Marseglia G, Sacco O, Ciprandi G. Immunotherapy and asthma in children. Front Pediatr. 2018;6:231. https://doi.org/10.3389/ fped.2018.0023

Excellent review article describing the biomarkers under investigation for AIT.

45. van Hage M, Hamsten C, Valenta R. ImmunoCAP assays: pros and cons in allergology. J Allergy Clin 
Immunol. 2017;140(4):974-7. https://doi.org/10. 1016/j.jaci.2017.05.008.

46. Buzzulini F, Da Re M, Scala E, et al. Evaluation of a new multiplex assay for allergy diagnosis. Clin Chim Acta. 2019;493:73-8. https://doi.org/10.1016/j.cca.2019. 02.025 .

47. Stringari G, Tripodi S, Caffarelli C, Dondi A, Asero R, Di Rienzo Businco A, et al. The effect of componentresolved diagnosis on specific immunotherapy prescription in children with hay fever. J Allergy Clin Immunol. 2014;134(1):75-81.

48. Tosca M, Silvestri M, Accogli A, Rossi GA, Ciprandi G. Serum- specific IgE and allergen immunotherapy in allergic children. Immunotherapy. 2014;6:29-33.

49. Wang W, Yin J. Is it worthy to take full-course immunotherapy for allergic rhinitis? About efficacy biomarker of allergen immunotherapy. Scand J Immunol. 2020;91(1):e12817. https://doi.org/10.1111/sji. 12817.

50. Fukano C, Ohashi-Doi K, Lund K, Nakao A, Masuyama K, Matsuoka T. Establishment of enzyme-linked immunosorbent facilitated antigen binding as a biomarker assay for Japanese cedar pollen allergy immunotherapy. J Pharmacol Sci. 2019;140(3):223-7.

51. Rebane A, Akdis CA. MicroRNAs: Essential players in the regulation of inflammation. J Allergy Clin Immunol. 2013;132(1):15-26.

52. Larenas-Linnemann DE, Mosges R. Dosing of European sublingual immunotherapy maintenance solutions relative to monthly recommended dosing of subcutaneous immunotherapy. Allergy Asthma Proc. 2016;37(1):50-6.

53. Moreno Benítez F, Espinazo Romeu M, Letrán Camacho A, Mas S, García-Cózar FJ, Tabar AI. Variation in allergen content in sublingual allergen immunotherapy with house dust mites. Allergy. 2015;70(11):1413-20.

54. Valenta R, Karaulov A, Niederberger V, Zhernov Y, Elisyutina O, Campana R, et al. Allergen extracts for in vivo diagnosis and treatment of allergy: is there a future? J Allergy Clin Immunol Pract. 2018;6(6):18451855.e2.

55. Esch R. Allergen extracts: composition, manufacture, and labeling. In: UpToDate. Post TW (editor). UpToDate, Waltham, MA. 2019. https://www. uptodate.com/contents/allergen-extracts-compositionmanufacture-and-labeling. Accessed 24 Feb 2020.

56. Zhernov Y, Curin M, Khaitov M, Karaulov A, Valenta R. Recombinant allergens for immunotherapy: state of the art. Curr Opin Allergy Clin Immunol. 2019;19(4):402-14. https://doi.org/10.1097/ACI. 0000000000000536.

57. Akdis CA, Blaser K. Bypassing IgE and targeting T cells for specific immunotherapy of allergy. Trends Immunol. 2001;22(4):175-8.

58. Norman PS, Lichtenstein LM, Kagey-Sobotka A, Marsh DG. Controlled evaluation of allergoid in the immunotherapy of ragweed hay fever. J Allergy Clin Immunol. 1982;70:248-60.

59. Riechelmann H, Schmutzhard J, van der Werf JF, et al. Efficacy and safety of a glutaraldehyde-modified house dust mite extract in allergic rhinitis. Am J Rhinol Allergy. 2010;24:e104-9.

60. Pfaar O, Nell MJ, Boot JD, et al. A randomized, 5 arm dose finding study with a mite allergoid SCIT in allergic rhinoconjunctivitis patients. Allergy. 2016;71:967-76.

61. Pfaar O, Robinson DS, Sager A, Emuzyte R. Immunotherapy with depigmented polymerized mixed tree pollen extract: a clinical trial and responder analysis. Allergy. 2010;65:1614-21.

62. Pfaar O, Urry Z, Robinson DS, et al. A randomized placebo controlled trial of rush preseasonal depigmented polymerized grass pollen immunotherapy. Allergy. 2012;67:272-9.

63. Eisenbarth SC, Colegio OR, O'Connor W, et al. Crucial role for the Nalp3 inflammasome in the immunostimulatory properties of aluminium adjuvants. Nature. 2008;453:1122-6.

64. Lu YC, Yeh WC, Ohashi PS. LPS/TLR4 signal transduction pathway. Cytokine. 2008;42:145-51.

65. Drachenberg KJ, Wheeler AW, Stuebner P, Horak F. A welltolerated grass pol- lenspecific allergy vaccine containing a novel adjuvant, monophosphoryl lipid A, reduces allergic symptoms after only four preseasonal injections. Allergy. 2001;56:498-505.

66. Basomba A, Tabar AI, de Rojas DH, et al. Allergen vaccination with a liposome- encapsulated extract of Dermatophagoides pteronyssinus: a randomized, double-blind, placebo-controlled trial in asthmatic patients. J Allergy Clin Immunol. 2002;109:943-8.

67. Klimek L, Willers J, Hammann-Haenni A, et al. Assessment of clinical efficacy of CYT003QbG10 in patients with allergic rhinoconjunctivitis: a phase IIb study. Clin Exp Allergy. 2011;41:1305-12.

68. Creticos PS, Schroeder JT, Hamilton RG, Balcer-Whaley SL, Khattignavong AP, Lindblad R, et al. Broide D; Immune Tolerance Network Group. Immunotherapy with a ragweed-toll-like receptor 9 agonist vaccine for allergic rhinitis. N Engl J Med. 2006;355(14):1445-55.

69. Thunberg S, Neimert-Andersson T, Cheng Q, Wermeling F, Bergström U, Swedin L, et al. Prolonged antigen-exposure with carbohydrate particle based vaccination prevents allergic immune responses in sensitized mice. Allergy. 2009;64(6):919-26.

70. Holt PG, Sly PD, Sampson HA, Robinson P, Loh R, Lowenstein H, et al. Prophylactic use of sublingual allergen immunotherapy in high-risk children: a pilot study. J Allergy Clin Immunol. 2013;132:991-3.

71. Kim JM, Lin SY, Suarez-Cuervo C, Chelladurai Y, Ramanathan M, Segal JB, et al. Allergen-specific immunotherapy for pediatric asthma and rhinoconjunctivitis: a systematic review. Pediatrics. 2013;131(6):1155-67. 
72. Cox LS, Larenas Linnemann D, Nolte H, Weldon D, Finegold I, Nelson HS. Sublingual immunotherapy: a comprehensive review. J Allergy Clin Immunol. 2006;117(5):1021-35.

73. Passalacqua G, Nowak-Węgrzyn A, Canonica GW. Local side effects of sublingual and oral immunotherapy. J Allergy Clin Immunol Pract. 2017;5(1):13-21. https://doi.org/10.1016/j.jaip.2016.06.020.

74. Winslow AW, Turbyville JC, Sublett JW, Sublett JL, Pollard SJ. Comparison of systemic reactions in rush, cluster, and standard-build aeroallergen immunotherapy. Ann Allergy Asthma Immunol. 2016;117(5):5425. https://doi.org/10.1016/j.anai.2016.09.005.
75. Jiang Z, Xiao H, Zhang H, Liu S, Meng J. Comparison of adverse events between cluster and conventional immunotherapy for allergic rhinitis patients with or without asthma: a systematic review and meta-analysis. Am J Otolaryngol. 2019;40(6):102269.

\section{Publisher's Note}

Springer Nature remains neutral with regard to jurisdictional claims in published maps and institutional affiliations. 